\title{
Analysis of Mechanical Properties of Low Density Polyethylene/Rice-Husk Composite using Micro Mathematical Model Equations.
}

\author{
Nwanonenyi, S.C ${ }^{1}$, Obidegwu, M.U² \\ ${ }^{1 \& 2}$ Department of Polymer and Textile Engineering, Federal University of Technology Owerri,
}

P.M.B. 1526 Owerri, Imo State, Nigeria.

\begin{abstract}
Density Polyethylene and Rice-Husk of $0.300 \mu \mathrm{m}$ particle size were melt-blended together by extrusion process and the mechanical properties of the composite were investigated using ASTM D638 test method with Instron testing machine of LK10K and model-3 type. Experimental results showed that tensile strength and percentage elongation of the composite exhibited a gradual decrease with increase in filler loading while tensile modulus and hardness showed gradual improvement with increase in filler loading. The correlative analysis of the mechanical properties of the composite was compared with the experimental results and the results from the micro mathematical model equations. The result showed that there is a distinct variation between the experiment results and results from micro mathematical model equations. The mechanical properties of the composite indicate that it may useful in some applications that require low strength, high stiffness and hardness.
\end{abstract}

Key Word - Composite, Filler Loading, Low Density Polyethylene, Mechanical Properties. Mathematical Model Equations, Rice-Husk,

\section{Introduction}

The use of natural fibers as particulate fillers are known to have different effects when combined with different thermoplastics, and in most cases, improve the impact strength, stiffness, heat distortion temperature and cost reduction [1]. In this regard, rice-husk/thermoplastics composites has been found to be of great relevance in automotive applications, building construction, control of environmental pollution and plastic composite either with or without the aid of some common compatibilizers. However, the pulverized rice-husk owes its outstanding modification effect on its dimensional stability, biodegradability, renewability, and compatibility [2]. Recent interests on the inadequate final disposal (open burning, land filling) of rice-husk, and its resistance to decomposition in the soil, difficult digestion and low nutritional value to animals has led to the development of a new product with thermoplastic and lignocellulosic material [3].

Various works on the application of natural fibers like Flax, hemp, jute, straw, wood fiber, wheat, barley, oats, cane (sugar and bamboo), grass reeds, kenaf, ramie, oil palm empty fruit bunch, sisal, coir, water hyacinth, pennywort, kapok, papermulberry, raphia, banana fiber, pineapple leaf fiber and papyrus as the reinforcing agent in plastic composites have been reported. For instances, there has been many reports on the use of wheat straw fibers for production of composites, panel boards and powdered wheat straw for anion exchangers [4]. Yang et al [5] investigated the effect of compatibilizing agents on the mechanical properties and morphology of thermoplastic polymer composites filled with rice husk flour and reported that compatibilizing agents improved the mechanical properties better. Madufor and Enyiegbulam [6] carried out a systematic study on the mechanical properties of LDPE/Cassava/Wood Four composites and pointed out that the composite is useful in furniture and allied products. Sapuan et al [7] reported the study on tensile and flexural strength of coconut spathe and sapthe fibre reinforced epoxy composite. The results showed that tensile strength of coconut sapthe-fibre is inferior to other natural fibre such as cotton, coconut coir and banana fibres, and suggest that fibre treatment may improve the interfacial bonding between fibre and matrix leading to better mechanical properties of coconut sapthe-fibre reinforced composite laminates. Sharifah, Martin, and Simon [8] studied the mechanical properties of composites manufactured from polyester resin with Kenaf fiber that blows to a height of at least 10 meter. Composites based on biologically degradable polyester amide and plant fiber (flax and cottons) with good mechanical properties, such as sufficient water resistance and biodegradability, have also been investigated by Jiang and Hinrichsen [9]. Generally, fine particles when well dispersed within the polymer resin improves the stiffness and impact behavior of the resin [1].

This work is aimed at effective utilization of rice husk wastes as particulate fillers in modification of thermoplastics to improve their impact strength, dimensional stability and moisture absorption characteristics, and provide an alternative and better way of disposing the rice husk waste 
IOSR Journal of Engineering

Mar. 2012, Vol. 2(3) pp: 399-407

\subsection{Experimental}

\subsection{Materials}

Materials used for the study include Low density polyethylene (with density of $0.922 \mathrm{~g} / \mathrm{cm}^{3}$, melt flow index (MFI) of $4.0 \mathrm{~g} / 10 \mathrm{~min}$ at $190^{\circ} \mathrm{C}$, produced by Thai Polyethylene Co Ltd, China), rice-husk wastes collected from a local farm at Atani, Ogbaru L.G.A. Anambra state, and the pulverizing machine used for break the rice-husk into particle size of $0.300 \mu \mathrm{m}$.

\subsection{Apparatus and Equipment}

This includes single screw extruder, universal instron testing machine, pulverizing machine, electronic weighing machine, dumb bell cutting machine, Hardness testing machine, sieve.

\subsection{Composite Preparation}

The rice-husk was sun-dried in an open air, grounded thoroughly and sieved to obtain a fine powder of $0.300 \mu \mathrm{m}$ diameters. LDPE and varying amount $(1,3,5,7 \mathrm{wt} \%)$ respectively of the rice husk powder were weighed using electronic weighing balance. Components of each composite sample were obtained using the formulations in Table 1.0 and combinations were done in \%wt. The composites were prepared using a single screw extruder fitted with a slit die at a mixing speed of 100rpm and extruding temperature of $130^{\circ} \mathrm{C}$, and cut to a dumb bell shape. Typical dimensions of dumb bell test samples were $135 \mathrm{~mm} \mathrm{X}$ $14 \mathrm{~mm} \times 2.0 \mathrm{~mm}$ as shown in Fig 1.0

Table 1.0: The formulation of the composite samples.

\begin{tabular}{|r|c|c|}
\hline \multicolumn{1}{|c|}{ ID } & LDPE (\%wt) & RICE-HUSK (\%wt) \\
\hline A & 100 & 0 \\
\hline B & 100 & 1 \\
\hline C & 100 & 3 \\
\hline D & 100 & 7 \\
\hline E & 100 & \\
\hline
\end{tabular}

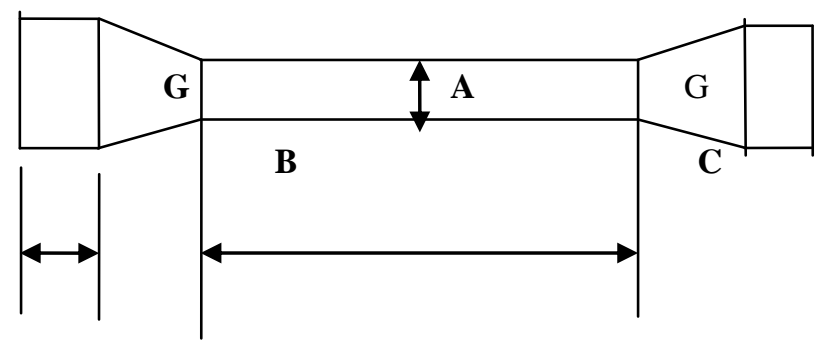

Figure 1.0 Dumb-bell shape sample

Where, $\mathrm{A}($ width $)=14 \mathrm{~mm}: \mathrm{B}($ gripping length $)=36 \mathrm{~mm}: \mathrm{C}($ gauge length $=135 \mathrm{~mm}$

Thickness $=2.0 \mathrm{~mm}$

\subsection{Property Measurement}

\subsection{Tensile Properties}

In determining the mechanical properties of the resultant composite, tensile tests were carried out at $25^{\circ} \mathrm{C}$ using a universal instron testing machine of LR10K and model-3 type in accordance with ASTM D638 specifications from which the tensile strength, percentage elongation, and tensile modulus values were obtained. Hardness test was determined using a Rockwell hardness tester according to ASTM D785 procedure.

ISSN: 2250-3021 
IOSR Journal of Engineering

Mar. 2012, Vol. 2(3) pp: 399-407

\subsubsection{Water Absorption Test}

Water absorption test was carried out in accordance with the ASTM D570 method. The test sample of dimension $50 \mathrm{X}$ $20 \mathrm{~mm}$ was first weighed in air and the dry weight was noted (X). The sample was later placed in a clean beaker, and $150 \mathrm{ml}$ of cold water was poured into the beaker which was immediately covered with filter paper and placed in a safe place. The sample was allowed to stay for 24 hours at room temperature. At the expiration of the required time, the wet sample was removed carefully from the beaker. Excess water on the surface of the test sample was wiped out with filter paper; care was taken during the wiping process to avoid removing the water absorbed by the sample. The sample was weighed again (Y). This process was repeated for other test samples. The percentage water absorption was calculated determined as follows;

Percentage Water Absorption $=(\mathrm{Y}-\mathrm{X}) / \mathrm{X}) \times 100 \%$.

Where $\mathrm{Y}=$ Weight of test sample after swelling, $\mathrm{X}=$ Dry weight of test sample.

\subsection{Results and Discussions.}

The plot of tensile strength with filler loading is shown in Fig 2.0 and Table 2.0. There was a significant decrease in tensile strength as filler loading increased. This is because incorporation of fine particles into the matrix in the absence of proper compatibilizing agents introduces brittleness into the composite and decreases the adhesion between filler and matrix. Thus, brittle materials exhibit low strength due to poor reinforcement when subjected to an increasing load. The tensile strength of composite materials were analyzed using the following mathematical models for mono-dispersed fillers [10].

$\delta_{\mathrm{C}}=\delta_{\mathrm{m}}\left(1-\mathrm{K} \Phi_{\mathrm{f}}^{2 / 3}\right)$

$\delta_{\mathrm{C}}=\delta_{\mathrm{m}}\left(1-\Phi_{\mathrm{f}}\right)$

$\delta_{\mathrm{C}}=\delta_{\mathrm{m}}\left(1-\Phi_{\mathrm{f}}^{2 / 3}\right)$

$\delta_{\mathrm{C}}=\delta_{\mathrm{m}}\left(1-\Phi_{\mathrm{f}}\right) . \mathrm{S}$

$\delta_{\mathrm{C}}=\delta_{\mathrm{m}}\left(1-\Phi_{\mathrm{f}}^{2 / 3}\right) \cdot \mathrm{S}^{1}$

$\delta_{\mathrm{C}}=\delta_{\mathrm{m}} \exp \left(-\alpha \Phi_{\mathrm{f}}\right)$

Where $\delta_{\mathrm{C}}=$ tensile strength of composite; $\delta_{\mathrm{m}}=$ tensile strength of matrix; $\Phi_{\mathrm{f}}=$ filler content (volume fraction); The superscript $2 / 3$ is a geometry related constant when the sample fails by random failure. $\mathrm{K}$ represents parameter measuring the adhesive strength of the bond between the matrix and the dispersed filler $(\mathrm{K}=1.21$ for spherical inclusions with a weak matrix adhesion). $S=$ parameter reflecting the weakening of the sample structure due to discontinuities of charge transfer. $S^{1}=$ parameter depending on stress concentrations $\left(S^{1}=1\right.$ means no stress concentrations; lower $S^{1}$ values reflect higher stress concentrations. $\alpha$ $=$ parameter describing stress concentration at interface. From Table 3.0 and Fig 3.0 the experimental results did not correlate with any of the mathematical model equations (1-6). The trend of the equations was a gradual decrease in tensile strength as the filler loading increased. Thus, indicating that adhesive strength of the composite collapsed with increase in filler loading as observed in equation 1 with $\mathrm{K}=5.031$. In equation (4), $\mathrm{S}=0.444$, reflecting the weakening of the structure as filler loading increased. Similar results were observed in equation (5), when $S^{1}=0.608$ indicating higher stress concentrations at interface. This higher stress concentrations at interface was confirmed by the value of $\alpha=18.67$ in equation (6). The observed decrease in tensile properties with addition of more filler may be explained by the fact that weak adhesion between the matrix and filler increases as more filler is incorporated into the composite.

From Fig.4.0 tensile elongation behaviour of the composite decreased with the increase in filler loading. The addition of the filler into the composite reduced the ductility of the matrix, and this brings about the decrease in elongation at break. Thus, increase in filler loading resulted in an increase in brittleness of the composite system. The general tensile elongation behaviour of polymeric composites with particulate fillers can be predicted by two mathematical model equations [10].

$\varepsilon_{\mathrm{c}}=\varepsilon_{\mathrm{m}}\left(1-\Phi_{\mathrm{f}}{ }^{1 / 3}\right)$

$\varepsilon_{\mathrm{c}}=\varepsilon_{\mathrm{m}}\left(1-\mathrm{K} \Phi_{\mathrm{f}}^{2 / 3}\right)$

Where $\varepsilon_{\mathrm{c},}=$ relative elongation at break of the composite and $\varepsilon_{\mathrm{m}}=$ relative elongation at break of the matrix. $\mathrm{K}=$ parameter depending on filler particle size and the applied treatment. Table 4.0 showed the comparison of the experimental results of relative elongation at break with the mathematical model equations (7-8). The experimental results correlate with equation (8), and the equations showed decreasing trend of elongation at break with increasing filler loading as observed in Fig 5.0. The tensile modulus increased with a corresponding increment in the filler loading as presented in Fig 6.0. The observed increase in the tensile modulus is due to improvement in the stiffness of the composite as filler loading increases. Some mathematical models equations [10] that predict the tensile (Young's) modulus of polymeric composites are as stated below;

$\mathrm{E}_{\mathrm{c}}=\mathrm{E}_{\mathrm{m}}(1+2.5 \Phi)$

$\left.\mathrm{E}_{\mathrm{c}}=\mathrm{E}_{\mathrm{m}}(1+2.5 \Phi)+14.10 \Phi^{2}\right)$ 
IOSR Journal of Engineering

Mar. 2012, Vol. 2(3) pp: 399-407

$\mathrm{E}_{\mathrm{c}}=\mathrm{E}_{\mathrm{m}}\left(1+2.5 \Phi+10.5 \Phi^{2}+0.0027 \exp (16.6 \Phi)\right)$

$\mathrm{E}_{\mathrm{c}}=\mathrm{E}_{\mathrm{m}}\left(1 /(1-1 / 2 \mathrm{~K} \Phi)^{2}\right)$

There are other background mathematical models equations [10] used for predicting of relative tensile modulus that are also very important. These models are stated below as follows;

$\mathrm{E}_{\mathrm{c}}=\mathrm{E}_{\mathrm{m}}\left(1-\Phi^{2 / 3}\right)$

$\mathrm{E}_{\mathrm{c}}=\mathrm{E}_{\mathrm{m}}\left(\left(1-\Phi^{2 / 3}\right) / 1-\Phi^{2 / 3}+\Phi\right)$

Where $\mathrm{E}_{\mathrm{c}}$, and $\mathrm{E}_{\mathrm{m}}$, are tensile modulus of the composite and the matrix respectively. $\Phi=$ filler content or volume fraction. Equation 10 is a modification of Equation 9 and it was developed to take care of high volume fraction of fillers in polymers filled with spherical particles. Equation (11) is an empirical relationship based on data generated by a mono-disperse spherical particle system whereas Equation (12) introduces a variable coefficient highlighting particle interactions and geometrical differences. Table 5.0and Fig 7.0 presented the comparison of the experimental results of relative tensile modulus with the mathematical model equations (9-14). The experimental results did not correlate with any of the equations, and the equations (9-11) showed increasing trend of tensile modulus with increasing filler loading whereas equations (12-14) deviated from the trend.

The hardness behaviour of the composite increased as filler loading increases (Fig 5.0). This result indicates enhancement of abrasion and impact behavior of the composite. Fig.6.0 presented that water absorption of the composite increased with increase in filler loading. The hydrophilic nature of the filler is believed to be responsible for the water absorption of the composite.

Table 2.0 : Effect of Rice-husk filler on some Mechanical properties of filled Low Density Polyethylene

\begin{tabular}{|c|l|l|l|l|l|}
\hline $\begin{array}{l}\text { Filler(\% } \\
)\end{array}$ & $\begin{array}{l}\text { Tensile Strength } \\
(\mathrm{MPa})\end{array}$ & $\begin{array}{l}\text { Elongation } \\
\text { at Yield } \\
(\%)\end{array}$ & $\begin{array}{l}\text { Elongation } \\
\text { at Break (\%) }\end{array}$ & $\begin{array}{l}\text { Tensile } \\
\text { Modulus (MPa) }\end{array}$ & $\begin{array}{l}\text { Shore A } \\
\text { Hardness }\end{array}$ \\
\hline 0 & 14.091 & 687.98 & 789.37 & 5.45 & 40 \\
\hline 1 & 10.143 & 534.26 & 687.86 & 5.97 & 43 \\
\hline 3 & 6.024 & 415.21 & 497.51 & 6.23 & 45 \\
\hline 5 & 4.382 & 325.48 & 385.05 & 7.20 & 47 \\
\hline 7 & 3.245 & 224.04 & 292.84 & 14.06 & 51 \\
\hline
\end{tabular}




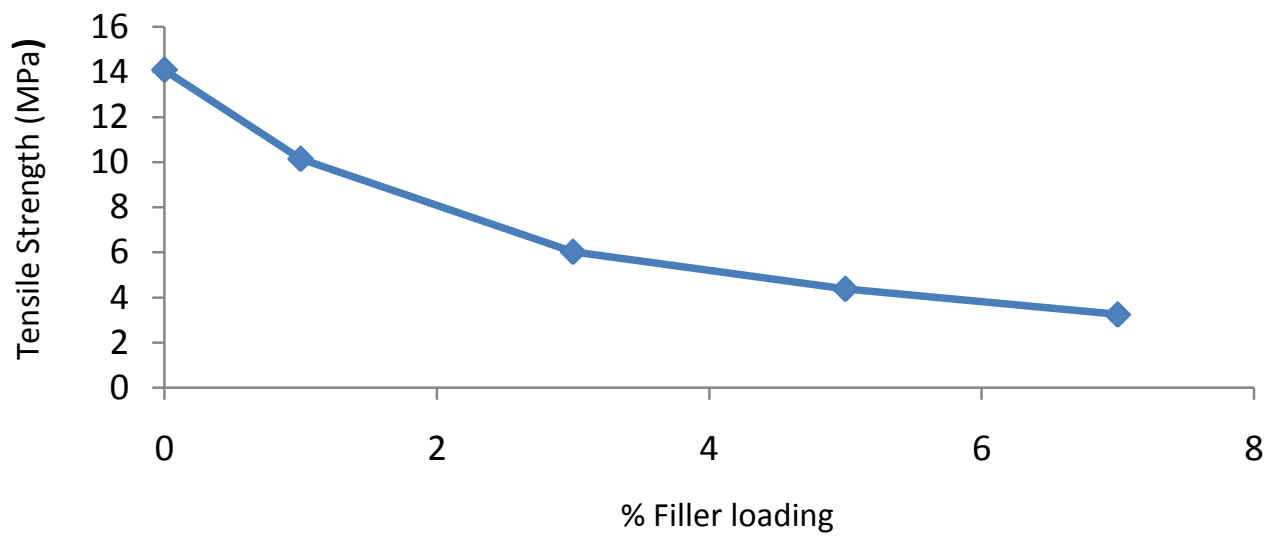

Fig 2.0 Tensile Strength of composite.

Table 3.0: Experimental Results (Tensile Strength) applied to Mathematical model equations (1-6)

\begin{tabular}{|c|l|l|l|l|l|l|l|}
\hline Filler(\%) & Exptal & Eq 1 & Eq2 & Eq3 & Eq4 & Eq5 & Eq6 \\
\hline 0 & 1 & 1 & 1 & 1 & 0.444 & 0.608 & 1 \\
\hline 1 & 0.7198 & 0.7701 & 0.9899 & 0.9543 & 0.4396 & 0.5802 & 0.8297 \\
\hline 3 & 0.4275 & 0.5200 & 0.9699 & 0.9046 & 0.4307 & 0.5400 & 0.5712 \\
\hline 5 & 0.3110 & 0.3258 & 0.9500 & 0.8660 & 0.4218 & 0.5265 & 0.3932 \\
\hline 7 & 0.2303 & 0.1553 & 0.9300 & 0.8316 & 0.4129 & 0.5056 & 0.2707 \\
\hline
\end{tabular}

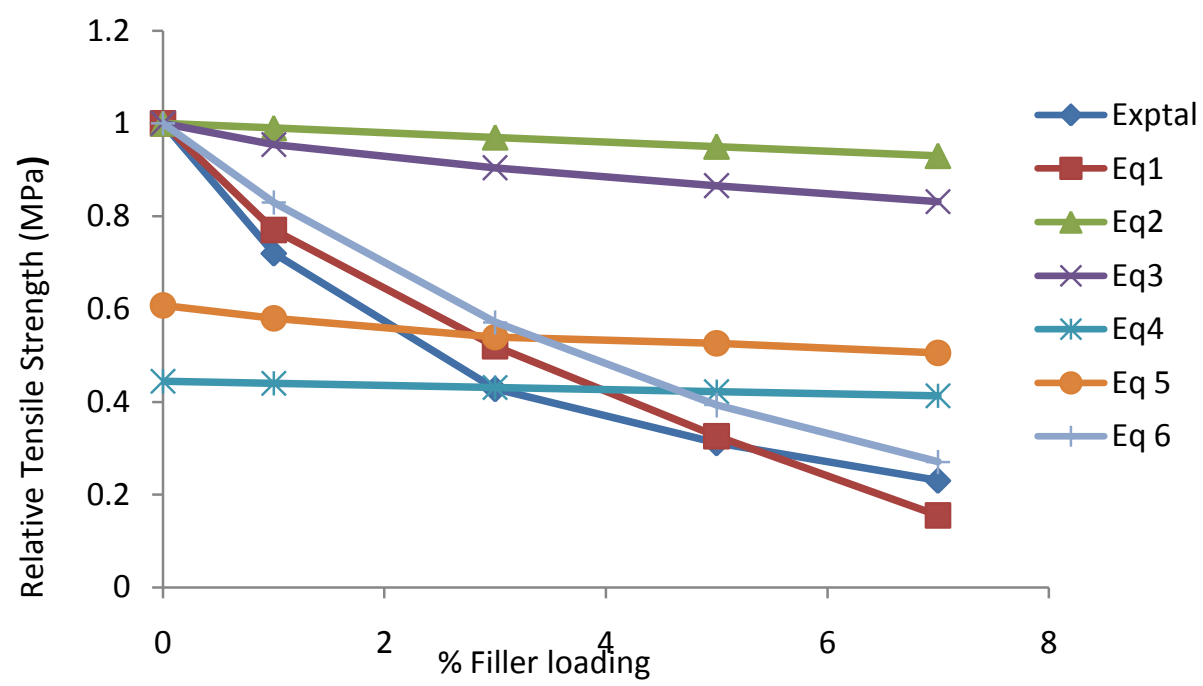

Fig 3.0 The plot of mathematical model equations (1-6) with the Experimental result.... 
IOSR Journal of Engineering

Mar. 2012, Vol. 2(3) pp: 399-407

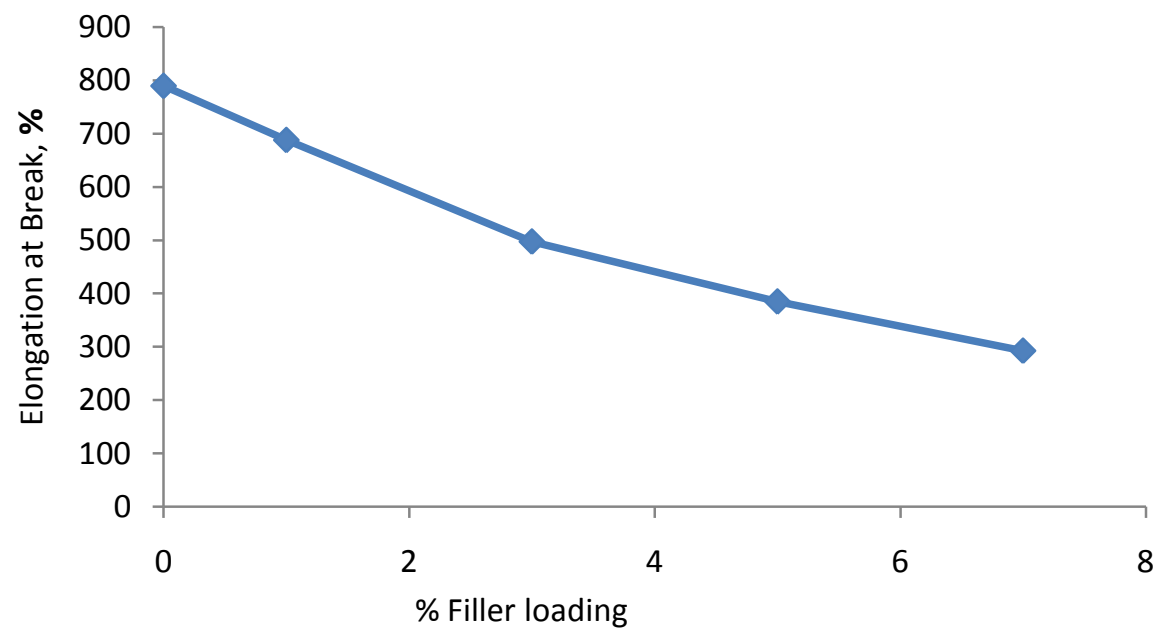

Fig 4.0 Elongation at Break(\%) against \% filler

Table 4.0 Experimental Results (elongation at break) applied to mathematical model equations (7-8)

\begin{tabular}{|l|c|c|c|}
\hline Filler (\%) & Exptal & Eq 7 & Eq 6 \\
\hline 0 & 1 & 1 & 1 \\
\hline 1 & 0.8714 & 0.784 & 0.828 \\
\hline 3 & 0.630 & 0.689 & 0.642 \\
\hline 5 & 0.488 & 0.631 & 0.496 \\
\hline 7 & 0.371 & 0.588 & 0.390 \\
\hline
\end{tabular}

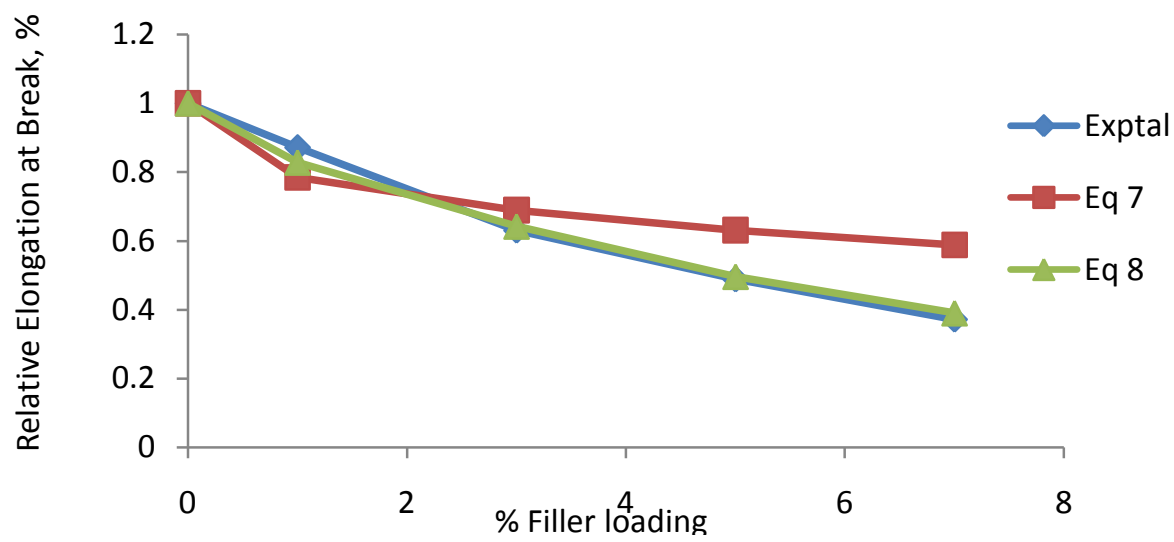

Fig 5.0 The plot of mathematical model equations (7-8) with the Exnerimental Result 


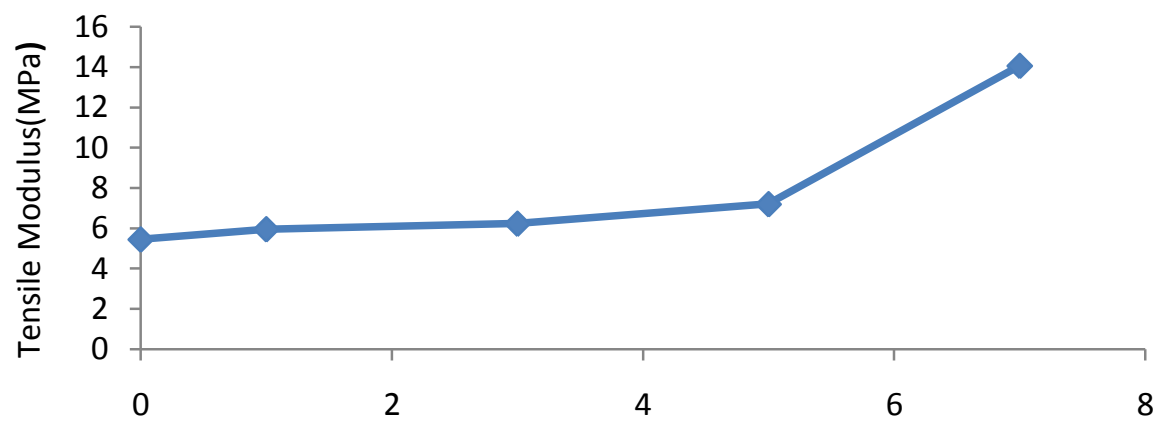

$\%$ Filler loading

Fig 6.0 Tensile modulus of composite Vs \% filler loading

Table5.0 Experimental results (tensile modulus) applied to Mathematical model equations (9-14)

\begin{tabular}{|l|l|l|l|l|l|l|l|}
\hline Filler (\%) & Exptal & Eq 9 & Eq10 & Eq11 & Eq12 & Eq13 & Eq14 \\
\hline 0 & 1 & 1 & 1 & 1 & 1 & 1 & 1 \\
\hline 1 & 1.095 & 1.025 & 1.026 & 1.029 & 0.849 & 0.954 & 0.990 \\
\hline 3 & 1.143 & 1.075 & 1.088 & 1.089 & 0.814 & 0.904 & 0.968 \\
\hline 5 & 1.321 & 1.125 & 1.160 & 1.156 & 0.489 & 0.864 & 0.945 \\
\hline 7 & 2.580 & 1.175 & 1.244 & 1.234 & 0.390 & 0.830 & 0.922 \\
\hline
\end{tabular}

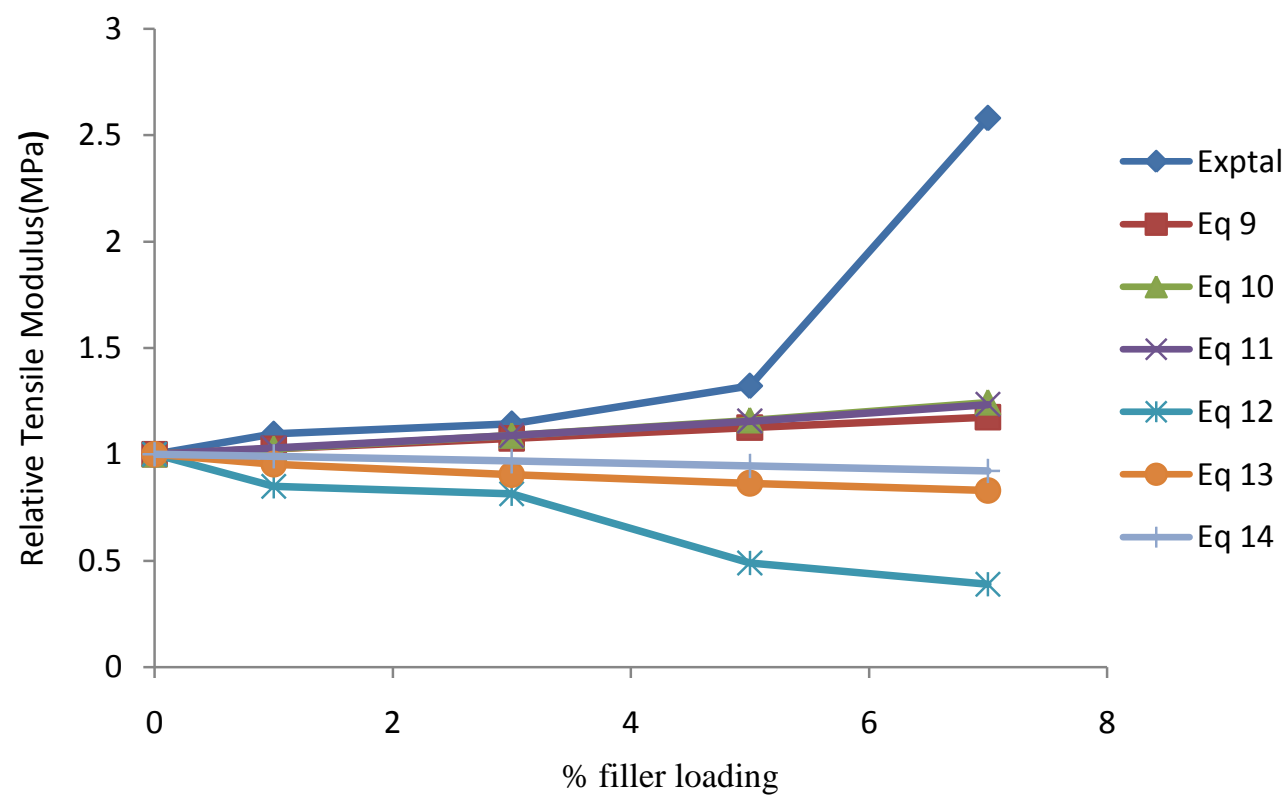

Fig 7.0: The plot of model equations (9-14) with the experimental results. 
IOSR Journal of Engineering

Mar. 2012, Vol. 2(3) pp: 399-407

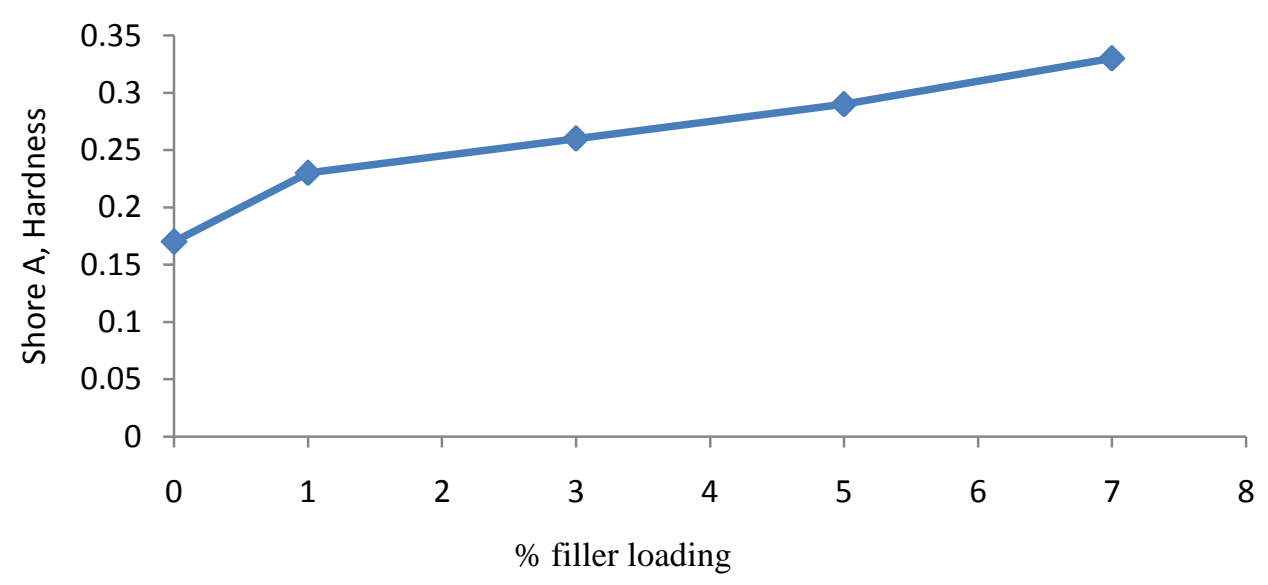

Fig 8.0: The plot of Shore A Hardness Vs \% Rice Filler

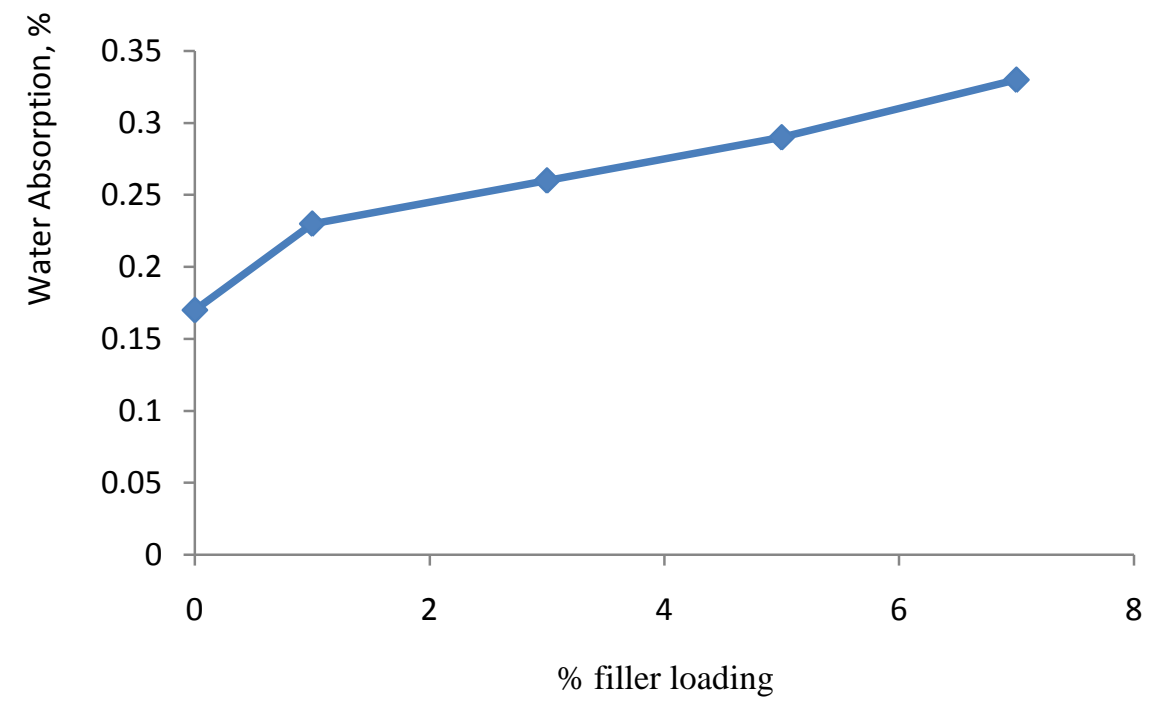

Fig 9.0: The plot of water absorption Vs \% filler

\subsection{Conclusion}

The incorporation of rice-husk into thermoplastic system enhances the stiffness and impact behaviour of the composite system. In addition, it creates a better means of disposing rice-husk which has being posing great challenge to our environment and farmers. The cost of rice husk is less than that of the plastic matrix in the composite developed, and the addition of the filler will result in significant material cost savings. The use of rice husk as filler, which otherwise is considered conventionally as waste can create a significant impact in plastic engineering. The incorporation of rice husk into low density polyethylene decreased the tensile strength and percentage elongation, and increased the water absorption of the composite, it therefore very important to select applications where low strength and level of water absorption by LDPE composite is not a critical factor such as in domestic products and electrical housing unit. 
IOSR Journal of Engineering

Mar. 2012, Vol. 2(3) pp: 399-407

\section{References}

[1] E.M. Katchy, Principles of Polymer Science ( EL'DEMAK Ltd, Nigeria, 2000)

[2] A. Maulida, M. Nasir, and H. P.Khalil, Hybrid Composite based on Natural Fiber, Proceedings of Symposium on Polymeric materials, Penang, 1-2, 2000, 216-219.

[3] Simone Maria Leal Rosa et al, Studies on the properties of Rice-husk-filled-PP composites - effect of Maleated PP” Mat. Res. 12(3), 2009,

[4] P. R Hornsby, E. Hinrichson, and K. Trivedi, Preparation and Properties of Polypropylene Composites Reinforced with Wheat and Flax Straw Fibers, Jour. Mater. Sci. 32, 1997,1009-1015.

[5] H.S. Yang, H. J. Kim, B.J. Lee and T. S. Hawng, Effect of Compatibilizing agent on Rice-husk Flour Reinforced Polypropylene Composites". Compos. Struct. 77, 2007, 45-55.

[6] I.C. Madufor, and M.E. Enyiegbulam, Mechanical Properties of LDPE/Cassava/Wood Composites ",International Journ. in Engr. Sc \& Tech (IREJEST) 4(2), 2007,74-80.

[7] S.M. Sapuan, M.N. Zan, E.S. Zainudin, and A. Prithvi, Tensile and Flexural Strengths of Coconut Spthe-fibre Reinforced Epoxy Composites, Journal of Tropical Agriculture. 43(1-2), 2005, 63-65.

[8] H.A. Sharifah, P.A Martin, T.C. Simon, and R.P. Simon, Modified Polyester Resins for Natural Fiber Composites". Compos. Sci. Technol. 65, 2005, 525-535.

[9] L. Jiang, and G. Hinrichsen, Flax and Cotton Fiber Reinforced Biodegradable Polyester amide”. Die Angew. Makromol.Chem. 268, 1999,13-17.

[10] I.C. Madufor, Mehcanical Properties of Cassava Filled Linear Low Density polyethylene”, International Journ. in Engr.Sc \& Tech (IREJEST), 4(2), 2007,143-151. 